\title{
High-Performance 40nm Gate Length InSb P-Channel Compressively Strained Quantum Well Field Effect Transistors for Low-Power $\left(\mathbf{V}_{\mathrm{CC}}=\mathbf{0 . 5 V}\right)$ Logic Applications
}

\author{
M. Radosavljevic, T. Ashley*, A. Andreev*, S. D. Coomber*, G. Dewey, M. T. Emeny*, M. Fearn*, \\ D. G. Hayes*, K. P. Hilton*, M. K. Hudait, R. Jefferies*, T. Martin*, R. Pillarisetty, W. Rachmady, \\ T. Rakshit, S. J. Smith*, M. J. Uren*, D. J. Wallis*, P. J. Wilding* and Robert Chau \\ Intel Corporation, Technology and Manufacturing Group, Hillsboro, OR 97124, USA \\ *QinetiQ, Malvern Technology Centre, St Andrew's Road, Malvern, WR14 3PS, UK \\ Contact: robert.s.chau@,intel.com
}

\begin{abstract}
This paper describes for the first time, a high-speed and low-power III-V p-channel QWFET using a compressively strained InSb QW structure. The InSb p-channel QW device structure, grown using solid source MBE, demonstrates a high hole mobility of $1,230 \mathrm{~cm}^{2} / \mathrm{V}$-s. The shortest $40 \mathrm{~nm}$ gate length $\left(\mathrm{L}_{\mathrm{G}}\right)$ transistors achieve peak transconductance $\left(\mathrm{G}_{\mathrm{m}}\right)$ of $510 \mu \mathrm{S} / \mu \mathrm{m}$ and cut-off frequency $\left(\mathrm{f}_{\mathrm{T}}\right)$ of $140 \mathrm{GHz}$ at supply voltage of $0.5 \mathrm{~V}$. These represent the highest $\mathrm{G}_{\mathrm{m}}$ and $\mathrm{f}_{\mathrm{T}}$ ever reported for III-V p-channel FETs. In addition, effective hole velocity of this device has been measured and compared to that of the standard strained Si p-channel MOSFET.

\section{Introduction}

The III-V compound semiconductor quantum-well field effect transistor (QWFET) is one of the most promising device candidates for future high-speed, low-power logic applications due to its high electron mobility. Recently, highperformance III-V n-channel QWFETs have been demonstrated [1-4]. However, for implementation of CMOS logic, there is a significant challenge of identifying high mobility III-V p-channel candidates [5]. In this work, we demonstrate for the first time a high-speed and low-power III-V p-channel QWFET using a compressively strained InSb QW structure, which achieves cut-off frequency $\left(\mathrm{f}_{\mathrm{T}}\right)$ of $140 \mathrm{GHz}$ at transistor gate length $\left(\mathrm{L}_{\mathrm{G}}\right)$ of $40 \mathrm{~nm}$ and supply voltage $\left(\mathrm{V}_{\mathrm{CC}}\right)$ of $0.5 \mathrm{~V}$. This represents the highest $\mathrm{f}_{\mathrm{T}}$ ever reported for III-V p-channel FETs.
\end{abstract}

\section{Materials Growth and Characterization}

Fig. 1 shows the InSb p-channel QW device structure used in this work. The structure is grown on (100) GaAs substrates using solid source MBE. The biaxial compressive strain in the InSb QW is modulated between 1.0-2.0\% using different $\mathrm{Al}$ composition in the $\mathrm{Al}_{\mathrm{x}} \mathrm{In}_{1-\mathrm{x}} \mathrm{Sb}$ barrier layers $(0.15 \leq x \leq 0.35)$. Fig. 2 shows the band diagram of InSb pchannel compressively strained QWFET, indicating hole carrier confinement in the QW layer. Fig. 3 shows the highresolution X-ray rocking curve from the (004) Bragg lines of InSb QWFET structure with different $\mathrm{Al}$ compositions in the barrier layers. The shift in angular position of the $\mathrm{Al}_{\mathrm{x}} \mathrm{In}_{1-\mathrm{x}} \mathrm{Sb}$ peak with respect to GaAs indicates increasing compressive strain in the InSb QW with increasing Al composition. Fig. 4 shows the 8-band k.p simulation of the in-plane effective hole mass as a function of energy for different compressive strain levels in the InSb QW. For a given energy, higher compressive strain results in lower in-plane effective hole mass. Fig. 5 shows the measured hole mobility vs. sheet carrier density for the $\mathrm{InSb} \mathrm{QW}$ at room temperature indicating mobility improvement with increasing compressive strain and remote doping. The highest InSb QW hole mobility of $1,230 \mathrm{~cm}^{2} / \mathrm{V}-\mathrm{s}$ is achieved with $1.9 \%$ compressive strain using $\mathrm{Al}_{0.35} \mathrm{In}_{0.65} \mathrm{Sb}$ barrier layers along with remote doping. This hole mobility is $>5 \mathrm{X}$ higher than that of standard strained Si p-channel MOSFET. Fig. 6 shows TEM image of the InSb p-channel 1.9\% compressively strained QWFET structure grown on GaAs substrate, which suggests that misfit and threading dislocations are predominantly contained in the bottom barrier layers.

\section{Device Fabrication and Characterization}

The TEM image in Fig. 7 shows the $40 \mathrm{~nm}$ gate length InSb p-channel QWFET with the $\mathrm{Al}_{0.35} \mathrm{In}_{0.65} \mathrm{Sb} / \mathrm{InSb}$ $\mathrm{QW} / \mathrm{Al}_{0.4} \mathrm{In}_{0.6} \mathrm{Sb}$ stack. Note that the measured hole mobility characteristic of this stack is matched to that of the $1.9 \%$ compressively strained InSb QW with remote doping in Fig. 5 . A wet etch is used for gate recess resulting in a $10 \mathrm{~nm}$ gateto-channel separation. $\mathrm{Ti} / \mathrm{Au}$ metallization is used for both gate and source/drain electrodes. Fig. 8 shows SEM micrograph of the same device. Fig. 9 shows drain current $\left(\mathrm{I}_{\mathrm{D}}\right)$ and gate leakage $\left(\mathrm{I}_{\mathrm{G}}\right)$ versus gate voltage $\left(\mathrm{V}_{\mathrm{G}}\right)$ of $\mathrm{p}$ channel InSb QWFET with $\mathrm{L}_{\mathrm{G}}=125 \mathrm{~nm}$. At $\mathrm{V}_{\mathrm{DS}}=-0.5 \mathrm{~V}$, the device exhibits threshold voltage $\left(\mathrm{V}_{\mathrm{T}}\right)=-0.01 \mathrm{~V}$, subthreshold slope $(\mathrm{SS})=90 \mathrm{mV} / \mathrm{dec}$ and drain induced barrier lowering $(\mathrm{DIBL})=80 \mathrm{mV} / \mathrm{V}$. SS and DIBL as a function of $\mathrm{L}_{\mathrm{G}}$ for $\mathrm{InSb}$ p-channel QWFETs are shown in Fig 10. Figs. 11 \& 12 show the $I_{D}-V_{G}$ and the $I_{D}-V_{D S}$ characteristics respectively of $\mathrm{InSb}$ p-channel QWFET for $\mathrm{L}_{\mathrm{G}}=40 \mathrm{~nm}$. Fig. 13 shows transconductance $\left(\mathrm{G}_{\mathrm{m}}\right)$ characteristics at $\mathrm{V}_{\mathrm{DS}}=-0.5 \mathrm{~V}$ of InSb p-channel QWFET with $\mathrm{L}_{\mathrm{G}}=40 \mathrm{~nm}$. The peak $\mathrm{G}_{\mathrm{m}}$ is $510 \mu \mathrm{S} / \mu \mathrm{m}$, which is the highest ever reported for III-V pchannel FETs. Fig. 14 shows current gain $\left(h_{21}\right)$ vs. frequency for the $40 \mathrm{~nm} \mathrm{~L}_{\mathrm{G}}$ InSb p-channel compressively strained QWFET, which achieves $\mathrm{f}_{\mathrm{T}}=140 \mathrm{GHz}$ at $\mathrm{V}_{\mathrm{DS}}=-0.5 \mathrm{~V}$. This represents the highest $f_{T}$ ever reported for III-V p-channel FETs. 


\section{Benchmarking vs. Standard Strained Si p-MOSFETs} Figs. 15 and 16 show gate delay $(\mathrm{CV} / \mathrm{I})$ vs. $\mathrm{L}_{\mathrm{G}}$ and energydelay product $\left(\mathrm{CV}^{2} * \mathrm{CV} / \mathrm{I}\right)$ vs. $\mathrm{L}_{\mathrm{G}}$, respectively, of InSb pchannel compressively strained QWFETs compared to Si pchannel MOSFETs. Other III-V p-channel QWFET work are included for reference [6, 7]. Compared to Si p-MOSFETs, the InSb p-channel QWFETs in this work show a reduction in gate delay and a significant improvement in energy-delay product, which represents the energy-efficiency of the device. Fig. 17 shows the cut-off frequency $\left(\mathrm{f}_{\mathrm{T}}\right)$ as a function of $\mathrm{DC}$ power dissipation for InSb p-channel compressively strained QWFET with $\mathrm{L}_{\mathrm{G}}=40 \mathrm{~nm}$ at $\mathrm{V}_{\mathrm{DS}}=-0.5 \mathrm{~V}$ versus standard strained Si p-channel MOSFET transistor with $\mathrm{L}_{\mathrm{G}}=60 \mathrm{~nm}$ at $\mathrm{V}_{\mathrm{DS}}=-0.5 \mathrm{~V}$ and $-1.1 \mathrm{~V}$. Compared to $\mathrm{Si}$, InSb p-channel QWFET shows $\sim 10 \mathrm{X}$ lower power at the same speed, or $\sim 2 \mathrm{X}$ higher speed at matched power.

We have also extracted the effective hole velocity $\left(v_{\text {eff }}\right)$ for both InSb p-channel QWFET and strained Si p-channel MOSFETs. This effective velocity is related to the transistor drive current in absence of parasitic resistance. $V_{\text {eff }}$ is determined from the equation below $[8,9]$ :

$$
\mathbf{v}_{\text {eff }}=\mathbf{g}_{\mathrm{mi}} /\left(\mathbf{W C}_{\mathrm{gi}}\right)
$$

where $\mathrm{g}_{\mathrm{mi}}$ is the intrinsic saturated transconductance corrected for parasitic resistance, $\mathrm{W}$ is the width of the device, and $\mathrm{C}_{\mathrm{gi}}$ is the intrinsic gate capacitance per unit area. In this work, both $\mathrm{C}_{\mathrm{gi}}$ and $\mathrm{g}_{\mathrm{mi}}$ of the InSb and Si devices are determined using high-frequency measurements and a small signal equivalent circuit model [9-11]. The high frequency response of the devices was measured from 1 to $50 \mathrm{GHz}$. Fig. 18 shows that the measured $\mathrm{S}$ parameters of the InSb p-channel QWFET are matched (with an RMS error of less than 1\%) to its simulated $\mathrm{S}$ parameters based on the small signal equivalent circuit model. Fig. 19 shows the frequency independent signature of $\mathrm{C}_{\mathrm{GS}}$, which is the gate-source capacitance. Next, $\mathrm{C}_{\mathrm{gi}}$ is determined from the slope of the total gate capacitance $\left(\mathrm{C}_{\mathrm{GS}}+\mathrm{C}_{\mathrm{GD}}\right) / \mathrm{W}$ versus the various physical gate lengths of the devices where $\mathrm{C}_{\mathrm{GD}}$ is the gatedrain capacitance. The RMS error of less than $1 \%$ between measured and modeled $\mathrm{S}$ parameters and the frequency independent signature of small signal circuit elements allow for accurate extraction of $\mathrm{g}_{\mathrm{mi}}, \mathrm{C}_{\mathrm{gi}}$, and thus the effective hole velocity of both InSb and Si. Fig. 20 shows the effective hole velocity $\left(\mathrm{v}_{\text {eff }}\right)$ vs. DIBL comparing InSb p-channel QWFETs to strained Si p-channel MOSFETs at $\mathrm{V}_{\mathrm{DS}}=-0.5 \mathrm{~V}$ and $\mid \mathrm{V}_{\mathrm{G}^{-}}$ $\mathrm{V}_{\mathrm{T}}=0.3 \mathrm{~V}$. It is observed that $\mathrm{V}_{\text {eff }}$ in InSb p-channel QWFETs is $>2 \mathrm{X}$ higher than that of strained Si p-channel MOSFETs for the same DIBL, demonstrating the intrinsic advantages of InSb p-channel QWFETs over Si p-channel MOSFETs. Further improvement in $v_{\text {eff }}$ of the p-channel InSb QWFET for a given DIBL will require further optimization of the device such as reduction of the gate-to-channel separation and increase in strain.

\section{Conclusions}

High performance $40 \mathrm{~nm}$ gate length InSb p-channel compressively strained QWFETs have been fabricated and achieved $\mathrm{f}_{\mathrm{T}}=140 \mathrm{GHz}$ at $\mathrm{V}_{\mathrm{DS}}=-0.5 \mathrm{~V}$. Compared to standard strained Si p-MOSFET, the InSb p-channel QWFET exhibits $\sim 10 \mathrm{X}$ lower power dissipation for same speed, or $\sim 2 \mathrm{X}$ improvement in speed for same power dissipation. Furthermore, $v_{\text {eff }}$ in InSb p-channel QWFETs shows more than $2 \mathrm{X}$ improvement compared to strained $\mathrm{Si}$ p-channel MOSFETs for the same DIBL, demonstrating intrinsic advantages of InSb QWFETs as a PMOS option for the III-V CMOS configuration.

\section{References}

[1] S. Datta et al., IEDM Tech. Dig., pp.763-766 (2005).

[2] T Ashley et al., Electronics Lett., Vol. 43, pp.788-789 (2007).

[3] D.-H. Kim et al., IEDM Tech. Dig., pp.629-632 (2007).

[4] M. Hudait et al., IEDM Tech. Dig., pp.625-628 (2007).

[5] R. Chau et al., IEEE/CSICS Tech. Dig., pp. 17-20 (2005)

[6] J. B. Boos et al., Electronics Lett., Vol. 43, pp.834-835 (2007)

[7] H. Park, et al., Proc. IEEE/Cornell Conference on High Speed Semiconductor Devices, pp.101-110, (1989).

[8] A. Lochtefeld et al., IBM J. Res. \& Devel., Vol. 46, pp.347-357, (2002).

[9] G. Dewey el al., IEEE Elec Dev Lett., to be published Oct 2008.

[10] Y. L. Lai et al., IEEE MTTT-S Digest, pp. 1261-1264 (2001).

[11] P. M. White et al., IEEE Microwave and Guided Wave Lett., Vol. 3, pp. 453-454, (1993).

\begin{tabular}{|c|c|c|c|}
\hline Ti/Au Source & $\begin{array}{l}\text { Ti/Au } \\
\text { Gate }\end{array}$ & & Ti/Au Drain \\
\hline $6 n m$ p-doped & & low & sistance cap \\
\hline 10nm p-doped & & $A I_{x} \ln$ & b top barrier \\
\hline 3nm undoped & & $A I_{x} \mid n_{1-x}$ & top barrier \\
\hline Be $\delta$-doping & & & \\
\hline $7 \mathrm{~nm}$ undoped & & $A I_{x} I_{1-x}$ & spacer \\
\hline $5 \mathrm{~nm}$ InSb quan & well & & \\
\hline $3 \mu \mathrm{m}$ undoped & $\mathrm{Sb}$ bo & ttom b & \\
\hline $200 \mathrm{~nm} \mathrm{Al}_{y} \ln _{1-y} \mathrm{~S}$ & erfacia & al layer & \\
\hline Semi-insulatin & su & ate & \\
\hline
\end{tabular}

Fig. 1: Schematic of InSb p-channel compressively strained QWFET structure on GaAs. Al composition (x) in the barrier layers is varied from 0.15 to 0.35 to provide compressive strain and hole confinement in the InSb QW.

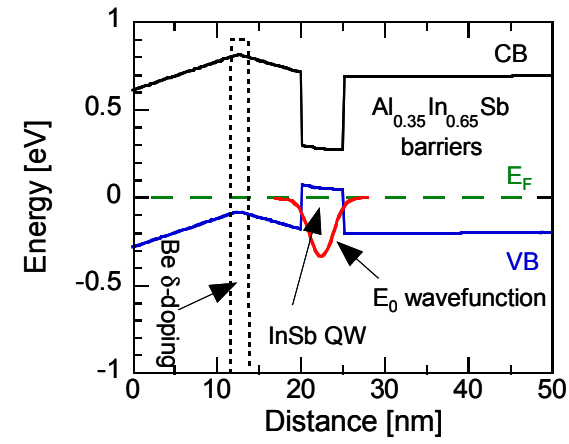

Fig. 2: Band diagram of InSb p-channel 1.9\% compressively strained QWFET obtained using 8-band k.p simulation, indicating hole carrier confinement in the QW layer. Valence band (VB), Fermi level $\left(\mathrm{E}_{\mathrm{F}}\right)$ and conduction band $(\mathrm{CB})$ are shown. 


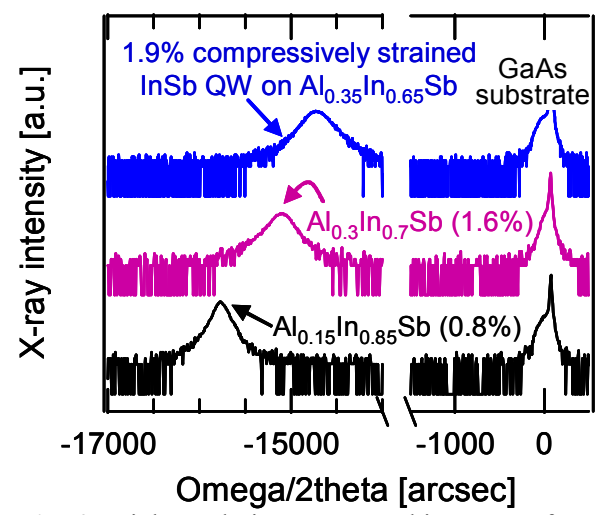

Fig. 3: High-resolution X-ray rocking curve from the (004) Bragg lines of InSb p-channel compressively strained QWFET structure with different $\mathrm{Al}$ compositions. The shift in angular position of the $\mathrm{Al}_{x} \mathrm{In}_{1-\mathrm{x}} \mathrm{Sb}$ peak with respect to GaAs indicates increasing compressive strain in the InSb QW with increasing Al composition.

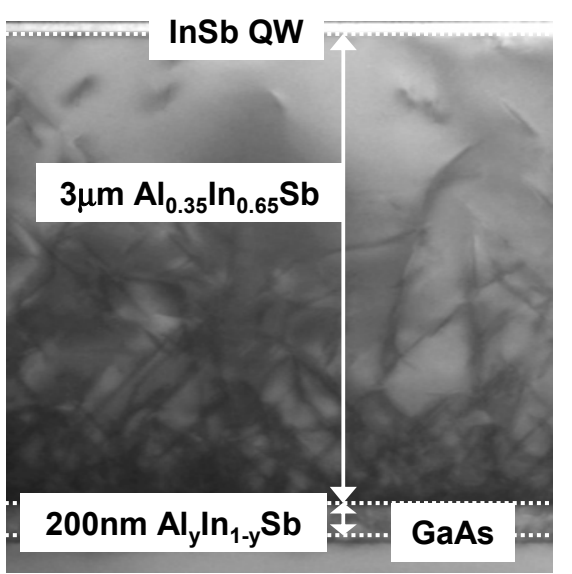

Fig. 6: Cross-sectional TEM image of InSb pchannel compressively strained QWFET structure grown on the (100) GaAs substrate. The misfit and threading dislocations are predominantly contained in the buffer layer.

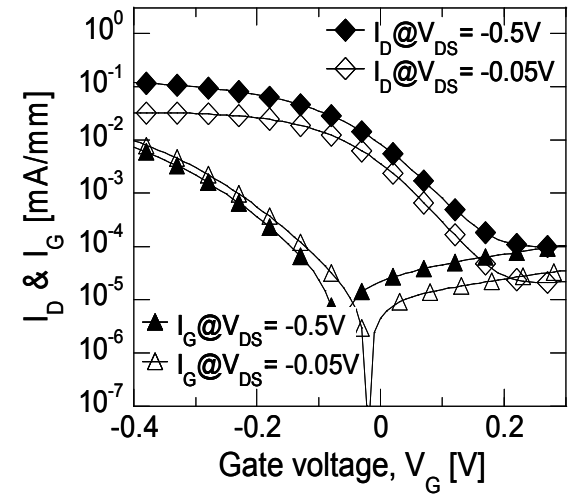

Fig. 9: Drain current $\left(I_{D}\right)$ and gate leakage $\left(I_{G}\right)$ versus gate voltage $\left(\mathrm{V}_{\mathrm{G}}\right)$ of InSb p-channel Fig. 10: Sub-threshold slope and DIBL as a compressively strained QWFET with $\mathrm{L}_{\mathrm{G}}=125 \mathrm{~nm}$. At function of $\mathrm{L}_{\mathrm{G}}$ for $\mathrm{InSb}$ p-channel $\mathrm{V}_{\mathrm{DS}}=-0.5 \mathrm{~V}$ the device shows threshold voltage $\left(\mathrm{V}_{\mathrm{T}}\right)$ compressively strained QWFETs. $=-0.01 \mathrm{~V}$, subthreshold slope $(\mathrm{SS})=90 \mathrm{mV} / \mathrm{dec}$ and drain induced barrier lowering $(\mathrm{DIBL})=80 \mathrm{mV} / \mathrm{V}$. results in lower effective hole mass. barrier, $\mathrm{InSb} \mathrm{QW}$ and $\mathrm{Al}_{0.4} \mathrm{In}_{0.6} \mathrm{Sb}$ top barrier.

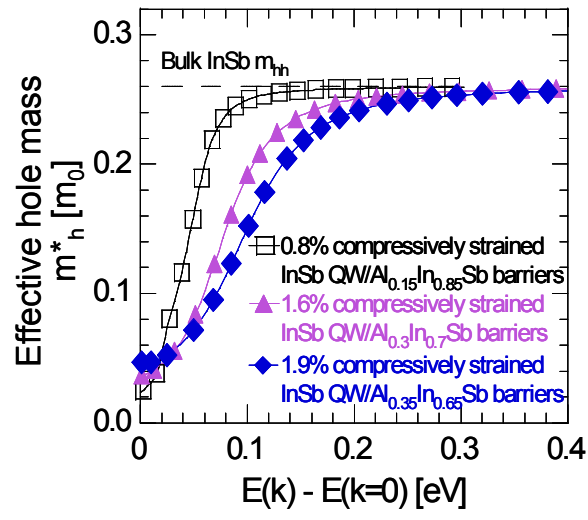

Fig. 4: 8-band k.p simulation of in-plane effective hole mass as a function of energy for different compressive strain levels in InSb QW. For a given energy, higher compressive strain

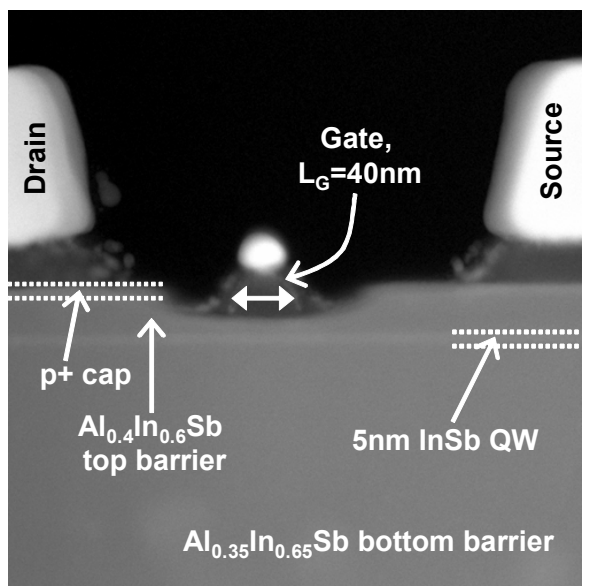

Fig. 7: High-magnification TEM image of the $40 \mathrm{~nm}$ gate length InSb p-channel compressively strained QWFET, showing the $\mathrm{Al}_{0.35} \mathrm{In}_{0.65} \mathrm{Sb}$ bottom
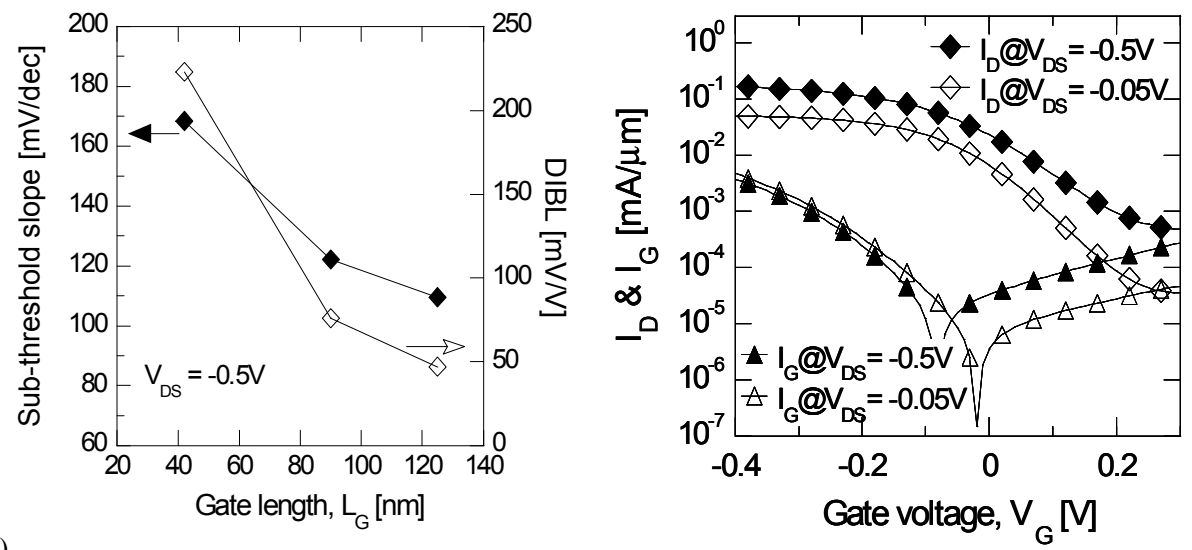

Fig. 11: $I_{D}$ and $I_{G}$ vs. $V_{G}$ of InSb p-channel compressively strained QWFET with $\mathrm{L}_{\mathrm{G}}=40 \mathrm{~nm}$. At $\mathrm{V}_{\mathrm{DS}}=-0.5 \mathrm{~V}$ the device shows $\mathrm{V}_{\mathrm{T}}=+0.03 \mathrm{~V}$, $\mathrm{SS}=160 \mathrm{mV} / \mathrm{dec}$ and $\mathrm{DIBL}=220 \mathrm{mV} / \mathrm{V}$. 


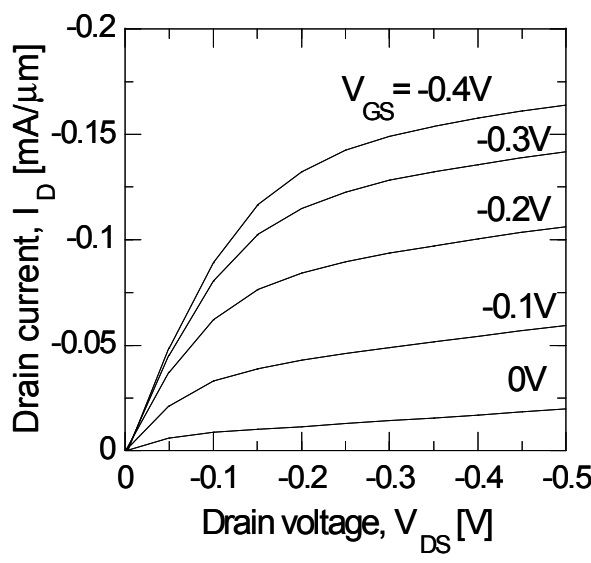

Fig. 12: $I_{D}-V_{D S}$ characteristics of InSb pchannel compressively strained QWFET with $\mathrm{L}_{\mathrm{G}}=40 \mathrm{~nm}$.

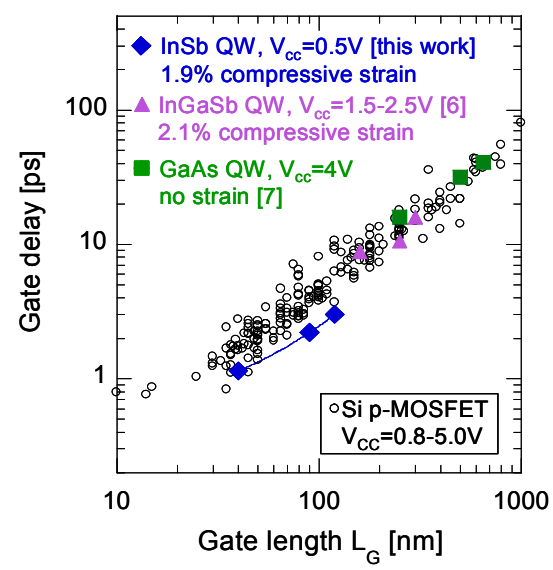

Fig. 13: Transconductance $\left(\mathrm{G}_{\mathrm{m}}\right)$ characteristics of $\mathrm{InSb}$ p-channel compressively strained QWFET with $\mathrm{L}_{\mathrm{G}}=40 \mathrm{~nm}$. Peak $\mathrm{G}_{\mathrm{m}}$ is $510 \mu \mathrm{S} / \mu \mathrm{m}$ at $\mathrm{V}_{\mathrm{DS}}=-0.5 \mathrm{~V}$, which is highest ever reported for III-V p-channel FET.

Fig. 15: Gate delay $(\mathrm{CV} / \mathrm{I})$ vs. $\mathrm{L}_{\mathrm{G}}$ of $\mathrm{InSb}$ p- Fig. 16: Energy-delay product vs. $\mathrm{L}_{\mathrm{G}}$ comparing channel compressively strained QWFETs InSb p-channel compressively strained compared to production and research $\mathrm{Si}$ p- QWFETs with production and research $\mathrm{Si}$ pMOSFET data. Other III-V p-channel QWFET work are included for reference $[6,7]$.

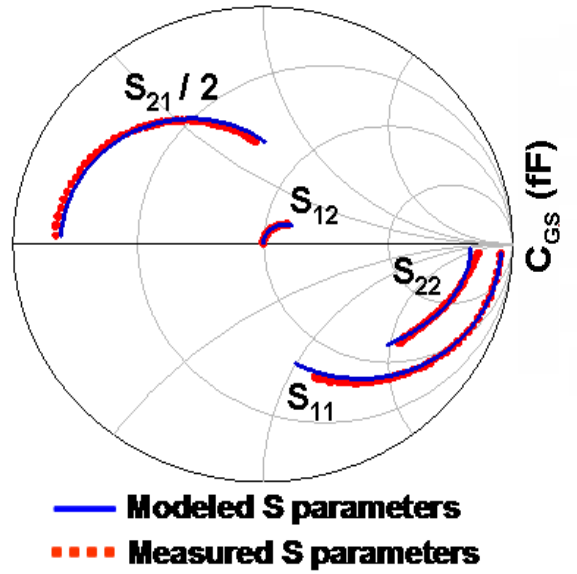

Fig. 18: Simulated $\mathrm{S}$ parameters based on a small signal equivalent circuit model and measured $\mathrm{S}$ parameters of the p-channel InSb QWFET from 1 to $50 \mathrm{GHz}$. The RMS error between measured and modeled $\mathrm{S}$ parameters is less than $1 \%$.
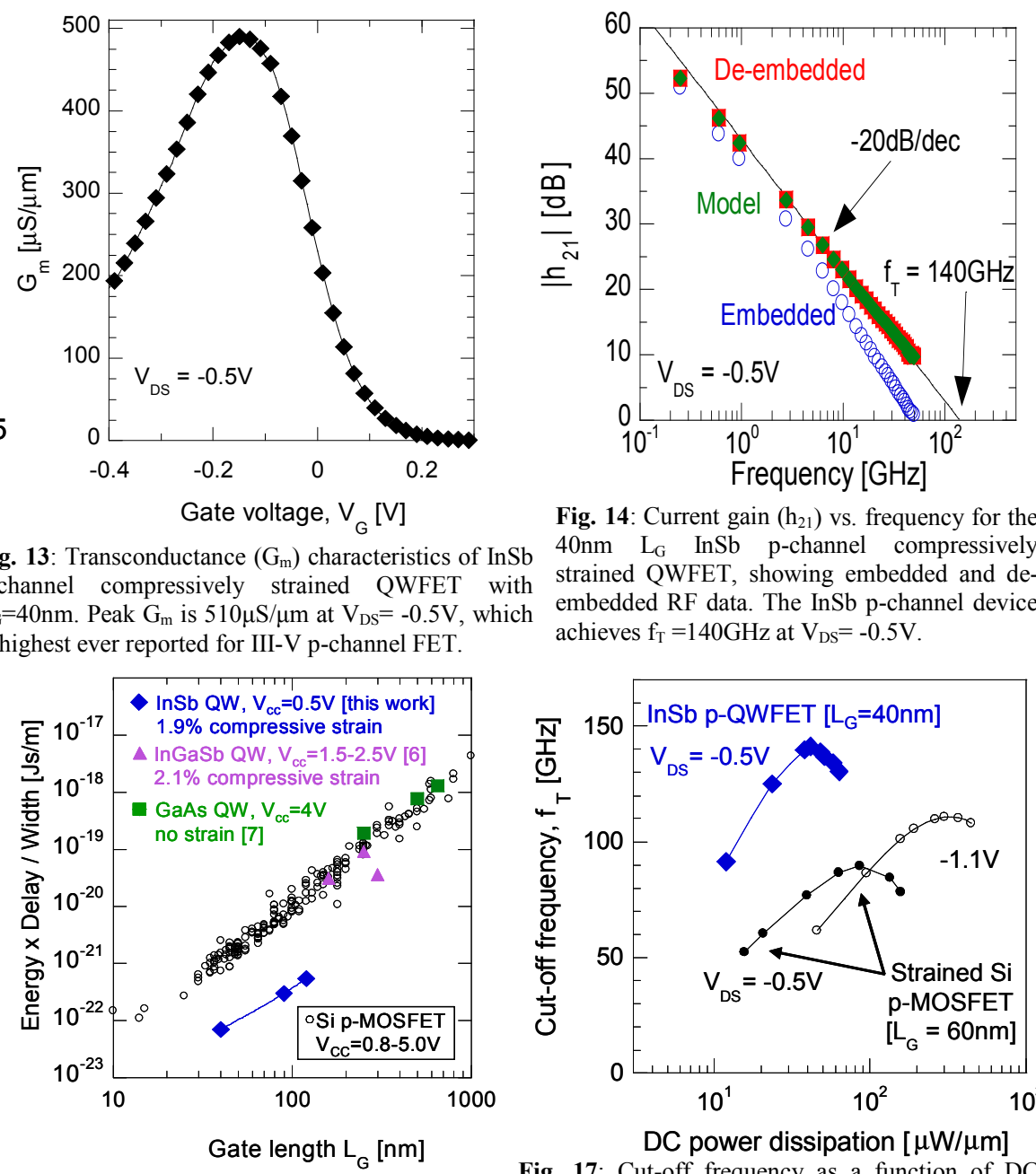

Fig. 14: Current gain $\left(h_{21}\right)$ vs. frequency for the 40nm $\mathrm{L}_{\mathrm{G}} \mathrm{InSb}$ p-channel compressively strained QWFET, showing embedded and deembedded RF data. The InSb p-channel device achieves $\mathrm{f}_{\mathrm{T}}=140 \mathrm{GHz}$ at $\mathrm{V}_{\mathrm{DS}}=-0.5 \mathrm{~V}$.

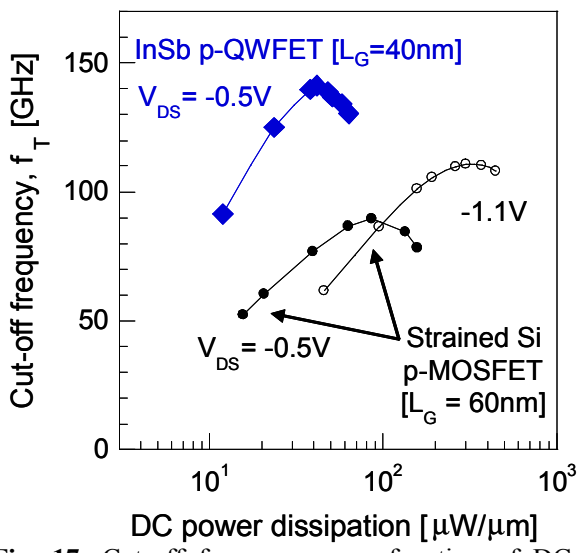

Fig. 17: Cut-off frequency as a function of DC power dissipation for InSb p-channel compressively strained QWFET with $\mathrm{L}_{\mathrm{G}}=40 \mathrm{~nm}$ at $\mathrm{V}_{\mathrm{DS}}=-0.5 \mathrm{~V}$ vs. standard strained Si p-channel MOSFET transistor with $\mathrm{L}_{\mathrm{G}}=60 \mathrm{~nm}$ at $\mathrm{V}_{\mathrm{DS}}=-0.5 \mathrm{~V}$ and $-1.1 \mathrm{~V}$. MOSFET data. Other III-V p-channe
work are included for reference $[6,7]$.

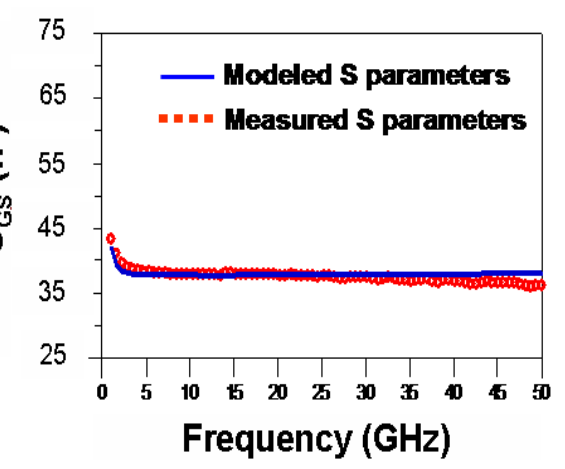

Fig. 19: Comparison between gate-tosource capacitance $\left(\mathrm{C}_{\mathrm{GS}}\right)$ simulated by the circuit model and extracted from the measured S-parameters of the p-channel InSb QWFET. The frequency independent nature of capacitance and other circuit elements allows accurate extraction of $\mathrm{v}_{\text {eff }}$.

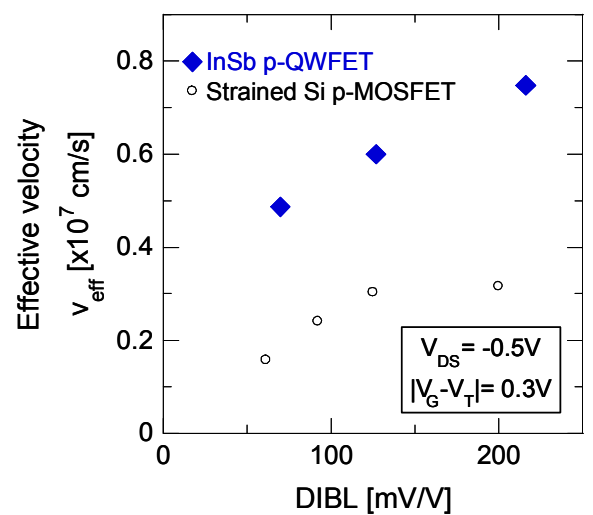

Fig. 20: Effective hole velocity ( $\left.\mathrm{v}_{\text {eff }}\right)$ vs. DIBL comparing InSb p-channel compressively strained QWFETs to strained Si p-channel MOSFETs at $\mathrm{V}_{\mathrm{DS}}=$ $-0.5 \mathrm{~V}$ and $\left|\mathrm{V}_{\mathrm{G}}-\mathrm{V}_{\mathrm{T}}\right|=0.3 \mathrm{~V}$. InSb p-channel QWFETs show more than $2 \mathrm{X}$ gain in $\mathrm{v}_{\text {eff }}$ over $\mathrm{Si}$ at matched DIBL. 